\title{
Analysis of Efficacy of Depo-Med Role Injection in Post- Operative Pain Relief for Lumbar Discectomy Patients
}

\author{
MUDASSIR RASHEED, AMMAR ANWER, SHAHZAD SHAMS \\ Department of Neurosurgery, King Edward Medical University/Mayo Hospital Lahore - Pakistan \\ DOI: https://doi.org/10.36552/pjns.v23i3.366
}

\begin{abstract}
Objectives: Discectomy for lumbar disc herniation is an effective treatment when conservative management doesn't work. Discectomy altogether eases pain just as radicular side effects after the activity. Nonetheless, pain in the lower back or in the leg due to radiculopathy is normal among larger part of patients who have undergone discectomy. The main objective of the study was to analyze the efficacy of Depo-medrole injection in postoperative pain relief after lumbar discectomy.

Material and Methods: This study was conducted in the Neurosurgery department of Mayo Hospital KEMU, Lahore during March 2018 to September 2018. The data was collected from 50 patients of lumbar discectomy randomly into two groups. One was operated patients and in group 2 patients were injected with local Depo-med role after lumbar discectomy. We studied the efficacy of Depo-med role injection in the second group. Pain intensity was measured using VAS from the whole sample at two weeks, four weeks, three months and last at one year post operatively.

Results: Data were collected from 50 patients. These patients were divided into two groups, 25 in group one and 25 in group two. The mean age of group one was $30.14 \pm 8.15$ and for group two was $29.82 \pm 7.16$. Both groups neither contrasted by age $(p=0.187)$ nor as indicated by term of side effects $(p=0.639)$ at the season of operation.
\end{abstract}

Conclusion: The usage of low dose Depo-med role decreased an abrupt lumbago and pain leg after surgery effectively. But it needs more observations due to small nonrandomized sample.

Key Words: Lumbar discectomy, Depo-medrole, Leg pain.

\section{INTRODUCTION}

Discectomy is a best option for management of lumbar pain due to intervertebral (IV) disc herniation, when all noninvasive methods fail. The IV disc resection altogether eases back pain just as radicular side effects after the activity. Nonetheless, a persistent pain in lumbar area or radicular pain in the lower limbs is normal among larger part of patients' undergone discectomy. Intensity of pain may vary between low to extreme, and it may lead to disability and activity limitation in postoperative cases. ${ }^{1}$ Some sufferers may build the postoperative necessity of use of Morphine or its derivatives as analgesics and make patients prone to reactions identified with these medications. ${ }^{2}$ Also the aggravation together with careful intercession may adversely impact the long haul results by starting fibrosis, which is viewed as one reason for the late appearance of pain. Along these lines, rather than picking up, patients lose the certainty and potential advantages after discectomy. ${ }^{3}$

Numerous patients experience relentless or intermittent back and leg pain following surgery. ${ }^{4}$ There are different types of steroids, which were used, but epidural steroids have been striving for a long time as an aide to a medical procedure in lumbar circle malady. Their utilization under these conditions has been an endeavor to diminish early post-operative provocative response and late scar arrangement so as to decrease postoperative pain. ${ }^{5-6}$ 


\section{Objectives of the Study}

The main objective of this research work is to analyze the effectiveness of Depo-med role injection in postoperative pain relief for lumbar discectomy patients.

\section{MATERIAL AND METHODS}

\section{Study Design}

This descriptive study was conducted in the Neurosurgery department of Mayo Hospital, King Edward Medical University, Lahore, during March 2018 to September 2018.

\section{Data Collection}

This study was conducted with the permission of ethical committee of the hospital. The data was collected from 50 patients of lumbar discectomy. The data was divided into two groups. Group 01: operation (lumbar discectomy) patients, and Group 2: operation plus local injection of Depo-med role.

In group 2 patients, we inject local Depo-med role after lumbar discectomy. We studied the efficacy of Depo-med role injection in second group patients. Postoperative intensity of pain by was recorded on VAS by both groups at around fourteen days, one month, and a fourth of a year, one year, and last follow-up after the task. The severity of pain was rated from 0 to 10. Once the pain alleviated in all patients; they were asked to walk rapidly and to proceed with their usual activities after the discharge on regular progress. Detailed Immediate post-operative symptomatic and follow up examinations of patients were done.

\section{Inclusion Criteria}

All patients with failed medical treatment and being candidate for disc surgery.

\section{Exclusion Criteria}

Patients with multiple comorbidities operated previously, patients multiple comorbidities, who refused to give concent.

\section{Statistical Analysis}

The data were evaluated by using SPSS version 21.0. We compared the values of both groups. $\mathrm{P}<0.05$ were considered statistically significant.

\section{RESULTS}

The data were collected from 50 patients. These patients were divided into two groups, 25 in group one and 25 in group two. The mean age of group one was $30.45 \pm 5.15$ years, and for group two was $29.82 \pm$ 7.16 years. According to statistics, the two groups neither contrasted by age nor as indicated by term of side effects $(p=0.639)$ at the season of operation.

Table 1: Demographics values of selected patients.

\begin{tabular}{|l|l|l|}
\hline Parameters & \multicolumn{1}{|c|}{ Group 1 } & \multicolumn{1}{c|}{ Group 2 } \\
\hline Patients & 25 & 25 \\
\hline Gender & $12: 13$ & $12: 13$ \\
\hline Age & $35.45 \pm 5.15$ & $29.82 \pm 7.16$ \\
\hline Duration & $5.67 \pm 3.67$ & $5.19 \pm 3.54$ \\
\hline Pre-op & $7.12 \pm 0.45$ & $8.77 \pm 0.34$ \\
\hline 2-week follow up & $4.22 \pm 0.36$ & $2.96 \pm 0.38$ \\
\hline 1-month & $4.13 \pm 0.17$ & $2.64 \pm 0.21$ \\
\hline 3-month & $4.01 \pm 0.14$ & $2.80 \pm 0.19$ \\
\hline Final follow-up & $4.15 \pm 0.18$ & $3.5 \pm 0.20$ \\
\hline Follow-up & $30.55 \pm 5.17$ & $30.10 \pm 3.2$ \\
\hline
\end{tabular}

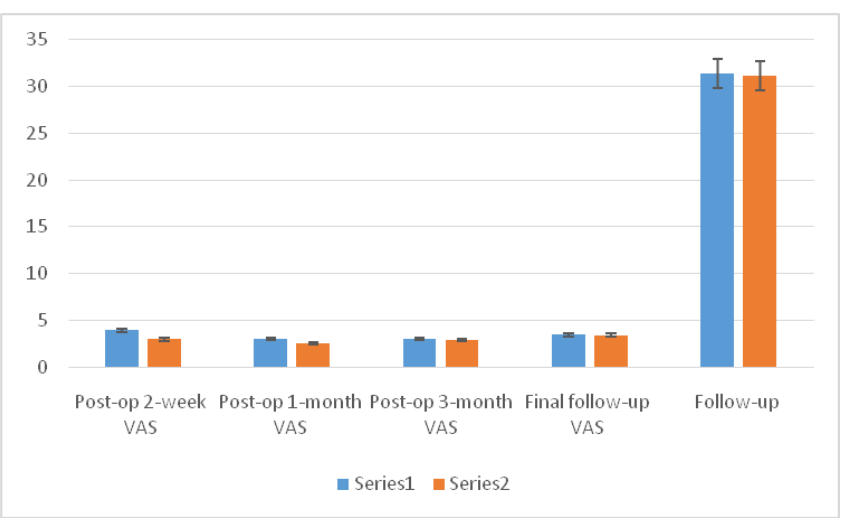

Fig. 1: Comparison of group 1 and group 2.

Anti-inflammatory, analgesic medicines were used to control pain and dosage was maintained uniformly. There were no patients who showed score $>5$ during the whole follow-up time period. 
Table 2: Analysis of duration of symptoms in group 2 patients.

\begin{tabular}{|c|c|c|c|c|c|c|}
\hline Sex & Age (Years) & Level & Duration (Weeks) & SLR & Pre & Post \\
\hline$M$ & 24 & $\mathrm{~L} 4-5$ & 2 & + & 7.9 & 2.6 \\
\hline M & 25 & $\mathrm{~L} 4-5$ & 5 & + & 7.7 & 3.1 \\
\hline M & 44 & $\mathrm{~L} 4-5$ & 7 & + & 8.2 & 3.2 \\
\hline M & 19 & $\mathrm{~L} 4-5$ & 8 & + & 8.3 & 2.9 \\
\hline M & 43 & $\mathrm{~L} 4-5$ & 9 & + & 8.5 & 3.1 \\
\hline M & 34 & $\mathrm{~L} 4-5$ & 5 & + & 8.6 & 3.3 \\
\hline $\mathrm{F}$ & 33 & $\mathrm{~L} 4-5$ & 4 & + & 7.6 & 3.2 \\
\hline M & 32 & $\mathrm{~L} 4-5$ & 2 & + & 6.9 & 2.9 \\
\hline M & 20 & $\mathrm{~L} 4-5$ & 3 & + & 7.6 & 2.8 \\
\hline $\mathrm{F}$ & 30 & $\mathrm{~L} 4-\mathrm{S} 1$ & 6 & + & 7.5 & 3.1 \\
\hline M & 20 & $\mathrm{~L} 4-5$ & 5 & + & 7.8 & 3.4 \\
\hline M & 24 & $\mathrm{~L} 4-5$ & 7 & + & 7.7 & 3.6 \\
\hline $\mathrm{F}$ & 22 & $\mathrm{~L} 3-\mathrm{S} 1$ & 6 & + & 6.6 & 3.2 \\
\hline M & 21 & L3 - S1 & 10 & + & 8.2 & 3.1 \\
\hline
\end{tabular}

\section{DISCUSSION}

Severe pain control following a medical procedure for degenerative lumbar malady is significant as it is connected with a diminishing in the rate of postoperative complications ${ }^{7}$. Pain following circle medical procedure is identified with various components that incorporate the fiery course which is activated by tissue injury and direct control of the nerve root. Intraoperative epidural steroids have been utilized as an adjuvant pain treatment in lumbar plate surgery. ${ }^{8}$ The last recommendation anyway was not supported by the investigation of Hackel et al. who announced that the use of epidural steroids was not related with lower frequency of scar arrangement or flopped back syndrome. -10 $^{-10}$

Intraoperative epidural steroids have been pushed for over two decades and notwithstanding the production of various preliminaries their utilization is as yet thought about a matter of discussion. Ranguis et al. distributed the primary methodical audit of 12 preliminaries on the theme in $2010 .{ }^{11}$ In any case, their meta-examination of information identified with back pain was restricted to 7 preliminaries, information identified with radicular pain was constrained to 5 preliminaries, information identified with postoperative utilization of absence of pain was restricted to 7 preliminaries and information identified with length of clinic stay was constrained to 4 trials. ${ }^{12}$

Lowell et al. noted for their situation report that utilization of epidural steroid after discectomy may incline to contamination. Nevertheless, we didn't watch any contamination in both groups. We trusted that the lower portions of methylprednisolone can't create contamination if severe aseptic safety measures, and prophylactic utilization of anti-infective agents are undertaken. $^{13}$

\section{CONCLUSION}

A nearby utilization of low dose Depo-med role lessens quick postoperative back and leg pain adequately with no danger of infection. Be that as it may, long haul impacts were not seen to be more advantageous than the control group.

\section{Additional Information}

Disclosures: Authors report no conflict of interest.

Human Subjects: Consent was obtained by all patients/ participants in this study.

Conflicts of Interest:

In compliance with the ICMJE uniform disclosure form, all authors declare the following: 
Financial Relationships: All authors have declared that they have no financial relationships at present or within the previous three years with any organizations that might have an interest in the submitted work.

Other Relationships: All authors have declared that there are no other relationships or activities that could appear to have influenced the submitted work.

\section{Address for Correspondence: Dr. Ammar Anwer Department of Neurosurgery King Edward Medical University/Mayo Hospital Lahore, Pakistan Email:ammaranwer@hotmail.com}

\section{REFERENCES}

1. Cherian MN, Mathews MP, Chandy MJ. Local wound infiltration with bupivacaine in lumbar laminectomy. Surg Neurol. 1997; 47 (2): 120-122.

2. Debi R, Halperin N, Mirovsky Y. Local application of steroids following lumbar discectomy. J Spinal Disord Tech. 2002; 15 (4): 273-276.

3. Ersayli DT, Gurbet A, Bekar A, Uckunkaya N, Bilgin H. Effects of perioperatively administered bupivacaine and bupivacaine-methyl prednisolone on pain after lumbar discectomy. Spine, 2006; 31 (19):2221 -2226.

4. Glasser RS, Knego RS, Delashaw JB, Fessler RG. The perioperative use of corticosteroids and bupivacaine in the management of lumbar disc disease. J Neurosurg. 1993; 78 (3): 383-387.

5. Jirarattanaphochai K, Jung $\mathrm{S}$, Thienthong $\mathrm{S}$,
Krisanaprakornkit W, Sumananont C. Peridural methyl prednisolone and wound infiltration with bupivacaine for postoperative pain control after posterior lumbar spine surgery: a randomized double-blinded placebocontrolled trial. Spine, 15. 2007; 32 (6): 609-616.

6. Kawakami M, Tamaki T, Weinstein JN, Hashizume H, Nishi H, Meller ST. Pathomechanism of pain-related behavior produced by allografts of intervertebral disc in the rat. Spine, 1996; 21 (18): 2101-2107.

7. King JS. Dexamethasone-a helpful adjunct in management after lumbar discectomy. Neurosurgery, 1984; 14 (6): 697-700.

8. Lowell TD, Errico TJ, Eskenazi MS. Use of epidural steroids after discectomy may predispose to infection. Spine, 2000; 25 (4): 516-519.

9. Lundin A, Magnuson A, Axelsson K, Kogler H, Samuelsson L. The effect of perioperative corticosteroids on the outcome of microscopic lumbar disc surgery. Eur Spine J. 2003; 12 (6): 625-630. Doi: 10.1007/s00586-003-0554-7.

10. Mirzai H, Tekin I, Alincak H. Perioperative use of corticosteroid and bupivacaine combination in lumbar disc surgery: a randomized controlled trial. Spine, 2002; 27 (4): 343-346.

11. Mullen JB, Cook WA., Jr. Reduction of postoperative lumbar hemilaminectomy pain with Marcaine. Technical note. J Neurosurg. 1979; 51 (1): 126-127.

12. Murphy RW. Nerve roots and spinal nerves in degenerative disc disease. Clin Orthop. 1977; 129: 4660 .

13. Nachemson A. Intradiscal measurements of $\mathrm{pH}$ in patients with lumbar rhinopathies. Acta Orthop Scand. 1969; 40: 23-42.

\begin{tabular}{|c|c|c|c|}
\hline \multicolumn{4}{|c|}{ AUTHORSHIP AND CONTRIBUTION DECLARATION } \\
\hline Sr.\# & Author's Full Name & Intellectual/Contribution to Paper in Terms of: & \multirow{3}{*}{$\begin{array}{l}\text { Signature by } \\
\text { the author(s) }\end{array}$} \\
\hline 1. & $\begin{array}{l}\text { Mudassir Rasheed } \\
\text { (Main/Principal Author). }\end{array}$ & $\begin{array}{l}\text { 1. Proposed topics and Basic Study Design, } \\
\text { methodology. }\end{array}$ & \\
\hline 2. & $\begin{array}{l}\text { Ammar Anwer } \\
\text { (2nd Author) }\end{array}$ & $\begin{array}{l}\text { 2. Data collection and calculations, Analysis of data } \\
\text { and interpretation of results etc. }\end{array}$ & \\
\hline 3. & $\begin{array}{l}\text { Shahzad Shams } \\
\text { (3rd Author) }\end{array}$ & $\begin{array}{l}\text { 3. Literature review and manuscript writing, } \\
\text { referencing, Data Calculations and quality insurer }\end{array}$ & \\
\hline
\end{tabular}

Date of Submission: 06-07-2019

Date of Revision: 30-07-2019

Date of Online Publishing: 25-09-2019

Date of Print: 30-09-2019 